\title{
WRIGHT-CONVEXITY WITH RESPECT TO ARBITRARY MEANS
}

\section{MICHAE LEWICKI}

Abstract. Let $I \subset \mathbb{R}$ be an open interval and $M, N: I^{2} \longrightarrow I$ be means on $I$. We give sufficient conditions on means $M$ and $N$ under which every first Baire class solution $f: I \longrightarrow \mathbb{R}$ of the functional inequality

$$
f(M(x, y))+f(N(x, y)) \leqslant f(x)+f(y), \quad x, y \in I,
$$

is convex.

Mathematics subject classification (2000): 39B62, 39B82.

Key words and phrases: Wright convexity, Jensen convexity.

\section{REFERENCES}

[1] M. KUCZMA, An introduction to the Theory of Functional Equations and Inequalities, PWN, WarszawaKraków-Katowice 1985.

[2] S. ŁOJASIEWICZ, Wstẹp do teorii funkcji rzeczywistych, BM, tom 46.

[3] JANUSZ MATKOWSKI AND MAŁGORZATA WRÓBEL, A generalized a-Wright convexity and related functional equation, Ann. Math. Sil. 10, Katowice 1996, 7-12.

[4] Zs. PÁLES, On two variable functional inequalities, C.R. Math. Rep. Acad. Sci. Canada, Vol. 10 (1998), 25-28. 